\title{
Erratum to: In vitro RNA release from a human rhinovirus monitored by means of a molecular beacon and chip electrophoresis
}

\author{
Victor U. Weiss ${ }^{1}$. Christina Bliem ${ }^{1}$ - Irene Gösler ${ }^{2}$. Sofiya Fedosyuk ${ }^{2}$ • \\ Martin Kratzmeier $^{3}$ • Dieter Blaas ${ }^{2}$ - Günter Allmaier ${ }^{1}$
}

Received: 18 April 2016/Accepted: 18 April 2016/Published online: 25 April 2016

(C) Springer-Verlag Berlin Heidelberg 2016

\section{Erratum to: Anal Bioanal Chem}

DOI 10.1007/s00216-016-9459-2

The publisher regrets that the photo and biosketch of Prof. Günter Allmaier were missing from the original version of this article. The photo and biosketch are given below and the original article was corrected.

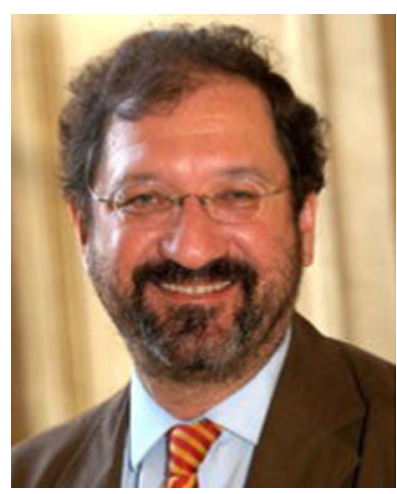

Günter Allmaier is Full Professor of Analytical Chemistry heading the research group Bio- and Polymer Analysis at the research division Instrumental Analytical Chemistry of Institute of Chemical Technologies and Analytics (TU Wien, Vienna, Austria). Furthermore he is acting as managing director of the Institute of Chemical Technologies and Analytics. He has been working since the beginning of the 1980s in the field of mass spectrometry and analysis of bioactive compounds with emphasis on therapeutic proteins and proteomics/lipidomics. During the last 15 years he has also been engaged in the field of electrophoretic separation in the liquid and gas phase of various classes of biomolecules and nano(bio)particles.

Our sincere apologies to the authors.

The online version of the original article can be found at http://dx.doi.org/ 10.1007/s00216-016-9459-2.

Günter Allmaier

guenter.allmaier@tuwien.ac.at

1 Institute of Chemical Technologies and Analytics, Vienna University of Technology (TU Wien), Getreidemarkt 9/164,

1060 Vienna, Austria

2 Department of Medical Biochemistry, Medical University of Vienna, Vienna Biocenter, Dr. Bohr-Gasse 9, 1030 Vienna, Austria

3 Agilent Technologies, Hewlett-Packard-Straße 8, 76337 Waldbronn, Germany 